Rev. Latinoam. Psicopat. Fund., São Paulo, v. 14, n. 2, p. 318-328, junho 2011

\title{
Estudo clínico sobre o medo dos espaços (agorafobia, dos alemães) - neurose emotiva*
}

Henri Legrand du Saulle

\section{Exposição. Denominação}

Sob o nome de medo dos espaços, descrevo hoje um estado neuropático muito particular, caracterizado por uma angústia, uma impressão ansiosa viva, ou mesmo um verdadeiro terror, que se produz subitamente em face de um determinado espaço. Este acidente nervoso é essencialmente emotivo. Ele nunca se acompanha da perda completa de consciência e de queda, e é totalmente distinto da hipocondria, da vertigem epilética, da vertigem estomacal e, sobretudo, da neuropatia cérebro-cardíaca. Provavelmente entrevisto por Griesinger, em 1868, ele foi assinalado cientificamente somente a partir de 1872 por Westphall, Cordes, S. Webber, Williams, Brown-Sequard e M. Perroud de Lyon, sob a designação de agorafobia, de angústia dos espaços e medo dos espaços.

Não posso adotar a expressão de agorafobia da qual se servem principalmente os alemães, porque ela limita o transtorno psíquico ao medo das praças públicas. Ora, as observações clínicas desses autores, e as minhas

* Publicado originalmente com o título "Étude clinique sur la peur des espaces (agorafobie, des allemands)- névrose émotive”. Libraires-éditeurs, Paris, 1878. (p. 1-76). As passagens aqui traduzidas correspondem ao que na edição de 1878 fora publicado nas páginas de 5-16 e de 23-25.

Tradução de Thais Guimarães Rodrigues e revisão técnica de Mario Eduardo Costa Pereira. 
próprias, estabelecem, ao contrário, assim como o veremos em um instante, que os doentes têm medo dos espaços, do vazio, e isso tanto na rua como no teatro, na igreja, em um andar um pouco elevado, em uma janela dando sobre um grande pátio ou sobre o campo, dentro de um ônibus, em um barco ou sobre uma ponte. Escolhendo o termo vago de "medo dos espaços" (peur des espaces), acredito dar uma ideia mais exata do fenômeno complexo que será exposto aqui, e me agrada pensar que esta denominação, substituta de agorafobia, não perderá absolutamente nada a ser expressa em francês.

\section{Sintomatologia}

O medo dos espaços, comumente compatível com todas aparências da mais perfeita saúde, se produz frequentemente no momento em que o neuropata sai de uma rua e entra numa praça. Ele se traduz por uma angústia repentina, um aperto no peito instantâneo. O doente, agora tomado por uma emoção indefinível, se encontra isolado do mundo inteiro, frente ao vazio que se oferece a ele e que é vivido como algo sem medidas. Mesmo apesar do pouco de fundamentos de seu pavor e apesar das mais sábias e tranquilizantes exortações que ele diz a si mesmo; sente-se aniquilado, não ousa sair da calçada, não faz um passo nem para frente nem para trás, todos seus membros tremem. Pálido, ele se arrepia, cora, cobre-se de suor, alarma-se cada vez mais, mal consegue se sustentar sobre suas pernas e fica dolorosamente convencido de que ele nunca poderá se confrontar com esse vazio, esse lugar deserto, e atravessar o espaço que a ele se apresenta. Caso venhamos a mergulhar nosso olhar em um buraco profundo, se nos imaginamos suspendidos em cima de uma cratera ardente, se cremos atravessar o Niagara sobre uma corda estendida ou ainda quando nos sentimos cair em um precipício, a impressão sentida não poderá ser mais dura, mais terrificante, do que essa provocada pelo medo dos espaços.

Porém nada impede o caminhar desse homem afobado que anda sem sair do lugar. O que ele demonstra é que, para fugir de seu terror, para se lembrar de sua calma normal e retomar sua coragem, basta a presença de uma companhia, do braço de alguém, da mão de uma criança, da aparição da luz de uma lanterna, da presença de um carro, do recurso possível a uma arma, do apoio de uma bengala ou mesmo da possessão de um guarda-chuva! Se o agorafóbico se aproxima de casas, ele se torna corajoso; se ele entra em uma rua estreita, sente-se mais sereno; se ele encontra uma pessoa conhecida, sente-se mais seguro, se ele não se sente mais sozinho, ele retoma sua coragem. O pensamento de ser abandonado no vazio o cristaliza de terror e a convicção de uma assistência, seja ela qual for, o acalma sem esforços. A visão inesperada de um espaço subtrai instanta- 
neamente suas forças e a confiança baseada na mais fugaz esperança. Não existe medo sem o vazio, não existe calma sem uma proteção aparente.

$\mathrm{O}$ medo dos espaços se produz igualmente nas ruas sem lojas ou nas quais as lojas estão fechadas, na igreja, no concerto, no teatro, na presença de grandes muralhas, de uma fachada monumental e lisa, de uma perspectiva penetrante, de uma ponte de numerosos arcos, de uma longa abóbada sustentada por colunas, em um lugar onde às vezes passa muita gente, em uma reunião ao ar livre, em um lugar a céu aberto, sem telhado e mesmo em um transporte público. Esse estado ansioso, que consiste, sobretudo, em um sentimento de medo exagerado e absurdo frente ao vazio, se acompanha comumente de fraqueza súbita das pernas, de superatividade circulatória passageira, de formigamentos vagos, de uma sensação de inchaço começando, de frio, de calor, de suor frio, de tremor, de vontade de chorar, de apreensões ridículas, de preocupações hipocondríacas, de lamentações murmuradas e de uma perturbação generalizada verdadeiramente penosa, com diversas alternativas de coloração facial e de expressão fisionômica. Ele não provoca ofuscamento, nem náuseas, nem vômitos, nem síncopes completas, nem sentimento de estrangulação, nem incontinência urinária, nem diarreia, nem excitabilidade delirante, nem impulsões inconscientes. A inteligência é sã e a liberdade moral intacta.

Do que o doente tem medo? De se perder, de chorar, de gritar, de cair, de ter uma vertigem, de desmaiar, de ter uma apoplexia, de ser considerado como um medroso, de ser alvo de riso dos outros, de se passar por um louco, de desaparecer para sempre, de entrar no inexistente, mas na maioria das vezes ele tem medo de... ter medo. Ele se dá conta exatamente da emoção que sente, da perturbação a qual está submetido, e raciocina, se culpabiliza e se encoraja, mas continua a ter medo, vê o espaço aumentar infinitamente, em uma perspectiva desmesurada, acredita que seus passos não o fazem avançar, que o vazio aumenta à medida que ele anda, e reencontra sua calma somente quando percebe a presença de um pedestre, apoiando-se em uma bengala ou no braço de alguém, andando ao longo da calçada, perto de casas ou em uma rua estreita. Se ele estiver muito preocupado com algo, voltado a uma grande reflexão ou distraído por uma notícia agradável, o medo, na mesma praça, não se manifestará. Se ele deixa a cidade e vai para o interior, em alguns casos, a visão das planícies verdes será suportada sem o menor mal-estar.

Todo fenômeno emotivo é, em geral, cheio de imprevistos, mas o que é necessário reconhecer e dizer, é que, no caso do medo dos espaços, o doente é mais apto a apresentar uma angústia quando está em jejum ou longe da hora de sua última refeição, e menos exposto a estar ansioso quando sai da mesa, quando jantou bem e tomou vinho generosamente.

Uma vez esboçadas estas características gerais da neurose, citamos alguns exemplos clínicos de apoio. 
Observação I - Senhora B..., 43 anos, mãe de três filhos bem-educados, pessoa de grande vivacidade, boa memória, notavelmente gentil. Ela é rodeada de pessoas e sempre bem-vinda: comenta-se sobre ela como alguém de uma rara fineza. Todos sabem que ela é supersticiosa, e todos se acostumaram a lidar com seus preconceitos e fragilidades. Ela nunca apresentou uma crise histérica e não é hipocondríaca.

Faz 15 anos que, logo depois de uma viagem na Suíça na qual subiu o Righi, ela não consegue atravessar os Champs-Elysées, as avenidas, uma grande praça ou uma rua larga, sem ao mesmo instante ser tomada por uma penosa angústia, por um medo estranho e ter seu corpo parcial ou inteiramente trêmulo. Ela se vê lacrimejar involuntariamente, lamenta-se em voz alta, sente suas pernas enfraquecerem ou tem a impressão de andar sobre um solo que se movimenta, mole e gorduroso. Ela sente como se afundasse em um solo de argila; como se o solo subisse e ela afundasse. "Nada dá voltas. Eu não me sinto enjoada, nem com vertigem. Eu tenho medo, só isso" - diz ela. Se dá o braço a seu marido ou a mão a seu filho mais velho, que tem dez anos, ela não apresenta nenhum mal-estar.

Essa senhora experimenta uma sensação idêntica ao entrar sozinha em uma igreja vazia, sobretudo se essa igreja não tem bancos, nem cadeiras; ela tem medo quando está em um carro, mas não há pedestres na rua. Durante o dia, é possível que ela peça para o zelador que lhe dê o braço e a acompanhe nas escadas largas que dão acesso a seu apartamento. Em uma grande sala do hotel onde toma seu café da manhã, ela é acometida de um medo terrível e com muita dificuldade consegue ir à estação de trem, que fica bem em frente de seu hotel. Ela analisa perfeitamente o que sente, reconhece o absurdo de suas angústias, tenta se acalmar, busca a razão, mas tem medo, geme e, em alguns minutos, entra em um estado de insuficiência, de espanto ou de excitação ridícula. Ela quase não ousa enumerar seus medos, pois tem receio de ser vista como alguém que sofre de perturbações da razão, mas quando fala e tenta se justificar, não encontra essa explicação: "Nesses momentos, devo provavelmente ter medo de morrer de forma súbita, de ter um ataque de apoplexia fulminante ou de uma síncope mortal. Caso contrário, seria louca, mas isso certamente eu não sou". Ela mora no fundo de um corredor muito grande. Não importa o que aconteça, ela nunca olha pela janela. Todos os cômodos de seu apartamento são cheios de móveis, de quadros, de esculturas e de tapetes. Vive numa verdadeira bagunça, e assim não se encontra nunca isolada e pode suportar a ausência dos seus. O vazio a aterroriza. Suas funções digestivas funcionam normalmente.

Todo antecedente mórbido em sua família foi formalmente negado, contudo o irmão da doente, morto com 18 anos de uma tuberculose pulmonar, era imbecil, masturbador e violento. Ele maltratava cruelmente os animais. E não foi possível que ele aprendesse a ler. 
Observação II - Sr. Albert G., 27 anos, tenente de infantaria, dotado de uma inteligência distinta, um bom leitor, sendo uma companhia agradável. Ele tem algumas pretensões à literatura, à poesia e à música e se diz arqueólogo. É de uma sobriedade exemplar e, aos vinte anos, em 1870, fora condecorado por um ato de bravura. Sua saúde sempre foi excelente, mas esteve coréico durante três meses, quando tinha uns treze anos e recorda perfeitamente de ter sido tratado por meio de ginástica, banhos sulfurosos e pelo uso de estricnina. Seu pai morreu de apoplexia, sua mãe apresentou alguns ataques convulsivos e uma de suas primas foi tratada durante três meses em um estabelecimento para alienados.

Em 1872, estando com sua guarnição na cidade, certa manhã ele atravessa, bem-vestido, uma praça pública absolutamente deserta e sente medo. Olha a seu redor, não vê ninguém, sente-se um pouco fraco e se pergunta se não deveria dar meia-volta. Hesita, por pouco não consegue guardar suas emoções, distingue muito claramente os objetos, mas treme e não consegue continuar. Um carro aparece na praça e logo o paciente recomeça a andar. Tendo entrado em uma rua estreita, sente-se à vontade e não padece de mais nada e nem presta atenção ao que acaba de acontecer.

Com alguns dias de intervalo, atravessa a mesma praça, na mesma hora, de uniforme, sua espada a seu lado, e não sente nada de particular. Depois de muitas outras tentativas, durante o dia ou à noite, percorre sem o mínimo mal-estar o mesmo caminho, a pé ou a cavalo.

Certo dia, vai visitar um de seus amigos, que mora no terceiro andar de um prédio, e o espera fumando um cigarro em sua varanda. Olha o vazio que o circunda, perturba-se, se preocupa, fica pálido, cora, treme, sai da varanda, entra no quarto, senta-se virado de costas para a janela, se acalma pouco a pouco, perde a paciência, desce as escadas sussurrando, caminha à vontade durante vinte minutos, chega a seu restaurante habitual, encontra seus colegas e janta com o melhor dos apetites.

Em uma manhã, participa de um exercício e recebe ordens de se distanciar por três quilômetros de onde estava, de encostar-se a um pequeno moinho, de traçar rapidamente o mapa do lugar e voltar imediatamente por um caminho que o conduzirá diretamente a um vilarejo. Lá, deverá reencontrar e juntar-se aos demais enviados para o reconhecimento e em seguida explicar o que viu aos batalhões que enfrentarão os inimigos. Ao chegar ao pequeno moinho, esse oficial começa a escrever. Fica apavorado ao ver a planície sem fim, treme e, muito pálido e fora de si, entra na casa do mercador de farinha, se diz indisposto por causa de uma insolação e pede uma xícara de leite. Ele é acolhido com benevolência, restabelecendo-se imediatamente. Dez minutos depois, sai, informa-se sobre a localidade com um jovem, ao qual pede para se sentar a seu lado enquanto desenha o mapa, depois agradece e parte. 
Muitas vezes, bem-vestido, atravessa a pé a mesma praça da primeira vez e experimenta a mesma angústia, enquanto que a cavalo ou em uniforme com uma espada ao lado, ele pode tranquilamente atravessá-la. Preocupado, inquieto, temendo ser visto, e talvez ser considerado um medroso, decide consultar um médico civil, que lhe prescreve a aplicação de sanguessugas sobre as apófises mastoides e de um purgativo salino todas as semanas durante três meses.

Em 1874, muda de guarnição e viaja com seu regimento. Depois de uma etapa de 33 quilômetros, chega a uma pequena cidade e se hospeda em frente de uma admirável igreja gótica. De fora, examina minuciosamente o monumento e em seguida entra na igreja, vê-se sozinho, tem medo, sente suas pernas fraquejarem, sente como se estivesse andando sobre um chão elástico. Senta, enxuga o rosto e geme. Depois de algum tempo, escuta alguém falando, levanta-se, se encoraja mentalmente, tenta se conter, não vê ninguém, caminha com dificuldade, sai da igreja, é saudado por três militares de seu regimento e quase imediatamente se sente recuperado. Ele não apresentou vertigens, nem náuseas, mas acredita ter sentido momentaneamente uma vontade imperiosa de ir ao banheiro.

Alguns dias depois, chega a seu destino e sente um forte mal-estar. Hospeda-se primeiramente em um prédio, no segundo andar, sobre um quintal. Em seguida, no primeiro andar sobre uma rua. Ele sofre de suas angústias muitas vezes. Seus colegas zombam das razões que alega para mudar de apartamento tantas vezes. Enfim, depois de muitas tentativas e de constante hesitação, aluga um apartamento. Deixa suas janelas fechadas, uma vela sempre acesa, dorme na parte de trás do apartamento e sai ou entra somente passando por um pequeno quintal. Dessa vez ele se sente bem e se comporta perfeitamente.

Em 1875, sente medo no grande pátio da caserna, e, como já houvera sido alvo de suposições depreciativas e de comentários estúpidos, ele se declara doente, ameaçado de grave apoplexia. Solicita longas férias e, em seguida, um afastamento do trabalho por razão de enfermidade temporária.

De volta a sua cidade natal, busca se ocupar, não costuma sair de casa, lê bastante e não sente absolutamente nada. Recebe a herança de seus pais e resiste aos vários projetos de casamentos que lhe foram propostos. "O que devo fazer, devo me casar? Tenho mais vontade do que mostro. Aqui ninguém pode imaginar que estou doente. $\mathrm{O}$ fato é que eu como e bebo bem e durmo ainda melhor. No entanto, devo ter algum tipo de desorganização latente do cérebro!" - me escreve.

Depois de um tratamento hidroterapêutico prolongado e uma medicação fraca em bromo, mas de longa duração sr. Albert G. voltou para o exército (primeiro de abril de 1877). Ele está curado? Acredito que não.

Depois dessa exposição preliminar das características gerais da neurose e depois da citação das minhas duas primeiras observações pessoais, devo, sem mais esperar, trazer os três fatos clínicos publicados em 1872, por Westphal, pois são 
esses três fatos que serviram inicialmente de base ao engenhoso trabalho do psiquiatra alemão, e que, em seguida, dirigiram as pesquisas de alguns autores a respeito dessa nova ordem de fenômenos emotivos. Trago aqui, a partir da tradução que fiz de todos os documentos impressos sobre essa questão no estrangeiro, o resumo bastante completo dos exemplos clínicos de Westphal (observação III, IV e V).

Observação III - M.C., caixeiro-viajante, 32 anos, altura mediana. Tem uma aparência saudável e sua conversa é cheia de animação. Desde que chega a uma praça pública, é acometido de um sentimento ansioso e de batimentos cardíacos acelerados. Ele tenta atravessá-la, mas tem a sensação de que nunca irá conseguir e, em seguida, começa a tremer involuntariamente. À medida que se aproxima das casas, ele se acalma. Quando dá o braço a alguém, sente-se muito menos abalado e não tem necessidade de se servir de uma bengala. Se está preocupado com algo, mergulhado em seus pensamentos, ele pode atravessar uma praça sem se abalar. A presença de um carro também o ajuda a atravessá-la, mas raramente não se abala diante de longas paredes, a uma caserna ou a uma rua cujas lojas estão fechadas. À noite, quando parte tarde do bar, ele espera ver uma pessoa tomar a mesma direção de sua casa e a segue passo a passo, ou então se aproxima de uma mulher em busca de aventuras e caminha ao seu lado. As lanternas vermelhas dos bares também lhe servem de apoio, mas se essas estão apagadas, ele para, estaciona e espera que um carro passe. Se estivesse em um campo um tanto vasto, cairia, diz o paciente, colaria seu rosto ao chão, e seguraria bem forte a grama. No teatro ou na igreja, já passou pelas mesmas sensações: é o espaço que causa sua ansiedade. Mas nada nele o inquieta especificamente. Ele se questiona e não encontra nenhuma explicação.

O que o acalma quando vê um carro, uma luz de bar acesa ou um pedestre é que ele pensa poder, em caso de acidente, entrar no carro, entrar no bar ou chamar o pedestre. Ele não sabe do que tem medo. Tem, verdadeiramente, medo de ter medo.

Não é uma vertigem que ele sente nesse momento. Já teve vertigens em outros momentos e reconhece que sua angústia atual é totalmente diferente. Não sente calor nem antes, nem depois da ansiedade, somente parece que ele cora. Seu mal-estar é bem mais forte em jejum que depois de uma refeição. Um ou dois copos de vinho ou de cerveja atenuam a crise.

M.C. liga a sua doença a 1866. A primeira manifestação se deu dessa forma: quando tinha vinte e sete anos, ele precisou ir um dia em uma casa construída na extremidade de uma larga avenida, longe das outras casas. De repente ele hesita, tem medo, não ousa se arriscar e volta. É somente mais tarde que começa a ter medo em ruas que não têm lojas. 
Até então, não havia apresentado qualquer problema e nunca teve síncopes ou convulsões. No entanto, havia tido, de vez em quando, algo como faíscas diante dos olhos e assim enxergava apenas metade dos objetos. Essas faíscas afetavam tanto o olho direito como o olho esquerdo e, às vezes, os dois olhos ao mesmo tempo. Este fenômeno, que poderia durar aproximadamente meia hora, cessava assim que ele colocasse suas mãos na água quente e não se acompanhava, nem era seguido de vertigens, de cefaléia, ou de vômitos.

M.C., exceto um leve tremor nas mãos e um tremor mais forte a cada pico de angústia, não apresenta nada de particular em relação a seu sistema nervoso. Ele não é hipocondríaco e se trata somente depois dos conselhos que seu médico lhe dá. Ele frequenta restaurantes e teatros. Não evita o encontro com mulheres, tendo sido contaminado várias vezes pela gonorreia.

Do ponto de vista físico, podemos notar algumas assimetrias: a sobrancelha esquerda é mais baixa que a direita; a abertura das pálpebras é maior do lado esquerdo; a púpila esquerda é mais dilatada que a direita, seja sob luz intensa, seja na escuridão; a vista é mais penetrante à esquerda; o olfato é menos sensível à esquerda; a metade esquerda do rosto é mais longa e mais estreita que a metade direita; a orelha esquerda é igualmente mais longa e mais estreita; a ponta da língua pende para a direita; a mão direita é mais larga que a esquerda; os dedos têm os mesmos comprimentos respectivos, mas são mais finos à esquerda; o braço direito é mais forte; o ombro direito é mais desenvolvido e mais baixo; o pé esquerdo é mais estreito e curvado; a panturrilha esquerda é mais fina; o tórax é mais liso à esquerda e mais largo.

Foi depois de uma sessão fotográfica que o próprio doente percebeu sua assimetria ocular. Um exame oftalmológico não trouxe nada de novo.

Seus pais são saudáveis. Nenhuma hereditariedade mórbida foi constatada ou confessada.

Observação IV - M.N., 24 anos, comerciante, tem medo de ser visto como louco e mal se atreve a falar sobre o que sente: para ele é impossível atravessar praças ou ruas cujas lojas estão fechadas, mas sua apreensão é menor se ele conta encontrar alguém que conhece. Ele não pode viajar de ônibus ou circular em transporte público, sendo assim forçado a circular somente com seu carro. Não fica em um teatro, concerto e em qualquer sala que seja muito grande e cheia de pessoas. Sente imediatamente uma angústia estranha, uma palpitação do coração, um tremor involuntário, um verdadeiro terror. Ele sente um calor inesperado subir de seu ventre até o alto de sua cabeça.

Se quer atravessar uma praça, o espaço parece crescer desproporcionalmente e seus passos parecem não o fazer avançar, independentemente de qualquer esforço que faça para se acalmar e mostrar a si mesmo o absurdo do fenômeno 
percebido. Ele sabe muito bem que não sente e nunca sentiu nenhuma vertigem, mesmo quando esteve nas montanhas ou nas geleiras. No entanto, nessas excursões, sempre esteve acompanhado de um amigo e sem este não teria se aventurado nem mesmo a um pequeno passeio. $O$ uso generoso de vinho ou um bom jantar diminuem seu medo.

Esse doente é inteligente, ativo, bem-dotado, alegre e disposto, mas mostra uma tendência evidente a se enfurecer. Ele não apresenta nenhuma anomalia física, exceto uma leve diminuição da memória. No entanto, teme perder a razão. Não é hipocondríaco, consegue dissimular um mal-estar, sobretudo depois de ter tido alguns ataques de epilepsia, alegando isso como motivo para não sair sozinho. Além disso, preocupa-se somente de suas angústias e não de sua antiga epilepsia.

Com 14 anos, apresentou sua primeira crise convulsiva, sendo as outras com 15 e 17 anos. Em seguida, com 18 anos, vieram várias outras acompanhadas de delírio passageiro. Tinha 23 anos quando teve a última crise. Todas as características clássicas da epilepsia foram observadas em seus ataques. M.N. atribui como origem de seu medo dos espaços algo que sua família dizia dele: "Ele não poderá ir sozinho por causa de seus ataques".

Esse doente estava predisposto hereditariamente às neuroses. Seu bisavô paterno, homem importante de sua época, ficou, depois de estudos prolongados, sem conseguir fazer nada durante dois anos, nem mesmo ler. Se falassem muito alto, ele entrava à noite em um estado cataléptico no qual ouvia tudo que acontecia a seu redor, mas sem poder se mexer. Nesse momento, as frases pronunciadas numa tonalidade muito alta soavam violentamente em seus ouvidos. Seu avô, dotado de uma grande inteligência, apresentou frequentemente sintomas como faíscas que interferem em seu campo visual. Também apresentava, diante de seus olhos, pequenos círculos brilhantes que cresciam, depois perdiam seu brilho e desapareciam saindo do seu campo visual. Os irmãos de seu pai foram conhecidos por suas distinções, sendo um deles um artista contemporâneo muito famoso. Os dois morreram de apoplexia e o terceiro de uma afecção cerebral desconhecida e não definida. Enfim, os irmãos e irmãs do doente alegam visualizar faíscas em seu campo de visão.

(...)

\section{Algumas particularidades relativas aos agorafóbicos}

Pôde-se perceber que o medo dos espaços se produzia, no caso de alguns doentes, em lugares muito frequentados ou em meio de uma multidão. A angústia é absolutamente a mesma que a experimentada diante de uma praça. Ela se impõe de repente e é acompanhada de forma quase invariável por esse pensamen- 
to: "Eu não posso sair, eu vou ter uma crise, todo mundo vai perceber e rir de mim, eu estou perdido!". Um agorafóbico, tratado por Cordes, encontrava-se ao teatro, quando se levanta bruscamente durante a representação e se afasta. No dia seguinte, quando seu médico o questiona sobre esse assunto e chama sua atenção por sua falta de confiança, ele lhe responde: "O que seria de mim se a sala começasse a pegar fogo e, se nesse exato momento, eu tivesse uma crise? Eu não teria podido me salvar!".

Resumiremos agora alguns casos trazidos por outros autores.

M. Dagonet citou em um encontro da Sociedade Médico-Psicológica o exemplo de um homem jovem muito instruído, professor de letras, vindo de uma família inteligente e que apresenta todos os fenômenos ligados ao medo dos espaços. Muitos dos familiares desse homem são excêntricos e mesmo alienados.

M. Delasiauve viu um doente, habitante de Gros-Caillou, que podia atravessar a ponte de Iéna ou dos Invalides somente se fixasse seu olhar em uma árvore ou uma casa do outro lado da ponte, e, ainda assim, não era sempre que conseguia. Ele mal conseguia entrar em um barco e sentia uma profunda ansiedade durante toda a duração do trajeto sobre a água.

Morel acompanhou, em 1845, um doente de quarenta anos, antigo oficial da guarda real, homem do mundo, conversador interessante, que não era de forma alguma alienado, mas que poderia ser facilmente considerado um excêntrico. Ele só podia morar no térreo. Se ele subisse sem se dar conta ao primeiro andar, era tomado por um medo intenso e se sentia como se estivesse sendo atirado em um precipício.

Os três ou quatro primeiros dias se passaram muito bem. O doente parecia feliz e nenhuma palavra sobre seu estado de saúde foi pronunciada, apenas percebi que ele analisava de forma inquieta a localidade e que buscava se informar se nas proximidades havia poços de água ou precipícios. Isso já começava a me preocupar e eu previa que a situação iria se complicar. As minhas apreensões se realizaram antes do previsto. Uma noite fui acordado por gritos terríveis. A doméstica que dormia perto de M.*** pedia socorro e quando cheguei, presenciei uma crise nervosa das mais intensas. M. *** gritava e soluçava, ele se agarrava tão fortemente a um empregado que o asfixiava. $O$ poço, o poço, ele exclamou com uma voz rouca ... o poço, tampe o poço. O que teria acontecido?

M.*** foi dormir tranquilamente e depois de alguns instantes perguntou a seu empregado o que eram as pranchas e os materiais que estavam acumulados em um canto do jardim, do lado de seu quarto. $\mathrm{O}$ empregado respondeu sem mistério que era de um poço que tinha sido tampado. O simples fato da associação mórbida entre a ideia do precipício e a impressão que ela causava em M.*** havia sido suficiente para desencadear a crise que eu descrevi. ${ }^{1}$

1. Arquivos gerais de medicina, abril 1866. 
Tal como relatado por Morel, esse doente tinha neuropatas em sua família. Seu irmão, por exemplo, era um desses espíritos covardes, limitado, sem energia, sem vontade, em cuja existência se apega a costumes tolos estereotipados e a tiques ridículos. Ele não ousava tocar moedas de cobre e, quando saía sozinho de carro, pagava o condutor com antecedência ou então embrulhava a soma a ser paga em um papel. Ele não abria nunca uma porta ou uma janela sem antes proteger suas mãos. No dia de seu casamento, ele foi procurado durante horas e horas, sendo encontrado no sótão encolhido atrás de um móvel antigo. O medo do encontro com sua mulher tinha sido suficiente para suspender o exercício de sua razão e provocar um fenômeno de automatismo estúpido. No entanto, ninguém ignora que certos neuropatas apresentam facilmente angústias análogas. Eles ficam imóveis diante de uma porta sem ousar a abrir; diante de uma carta sem retirá-la do envelope; diante de uma folha sem poder começar a escrever; diante de um carro sem ligá-lo etc.

Mas voltemos aos agorafóbicos. Alguns deles, depois de atravessar uma praça, não podem olhar para trás de si, nem retornar pelo mesmo caminho, sem serem tomados pelo mesmo terror. Outros, tranquilos em casa, conseguem, pela vivacidade de suas lembranças, pela concentração de seu pensamento e pelo poder de sua vontade, provocar uma cena de angústia idêntica àquela que poderiam ter experimentado em um lugar determinado. Basta que se isolem do mundo externo durante alguns instantes, que se lembrem claramente da situação angustiante e que se identifiquem com a impressão ressentida: a impressão reaparece, revive. Apesar de artificial e voluntário, o pânico ansioso é tão penoso e prolongado quanto teria sido o pânico acidental e involuntário.

O doente de Morel, que podia morar somente no térreo, havia evidentemente sentido o medo dos espaços na presença de um poço, de um grande buraco, de um abismo ou de um precipício. A notícia de que um poço tinha sido tampado perto de seu quarto causou a reprodução de sua ansiedade primeira. A reminiscência da emoção chamou a própria emoção. Na história psicopatológica das neuroses, qual o papel que a memória não tem!

\section{Henri Legrand du Saulle (1830-1886)}

Alienista francês do século XIX, autor de importantes estudos sobre medicina legal e sobre psicopatologia dos delírios e dos sintomas obsessivos. Em 1878, publica um dos textos mais importantes para a constituição da concepção contemporânea de agorafobia: "Estudo clínico do medo dos espaços (a agorafobia, dos alemães) - neurose emotiva". 